\title{
O DESAFIO DA GESTÃO DOS RESÍDUOS SÓLIDOS NOS MUNICÍPIOS BRASILEIROS: ESTUDO DO PROGRAMA ECOCIDADÃO PARANÁ
}

\section{THE CHALLENGE OF SOLID WASTE MANAGEMENT IN BRAZILIAN MUNICIPALITIES: STUDY OF THE PARANÁ ECOCIDADÃO PROGRAM}

\author{
Paloma Carvalho Zambon ${ }^{1}$ \\ José Edmilson de Souza Lima²
}

\section{RESUMO}

A partir da Lei 12.305/10, que instituiu a Política Nacional de Resíduos Sólidos, tornou-se dever dos municípios elaborar planos de gestão de resíduos sólidos, fomentar a criação e o fortalecimento de cooperativas e associações de catadores de materiais reutilizáveis e recicláveis, entre outros diversos instrumentos que buscam garantir a gestão adequada dos resíduos sólidos. O Programa Ecocidadão Paraná se propõe a auxiliar as Cooperativas e Associações de catadores de materiais recicláveis e reutilizáveis, a fim de promover o fortalecimento desse segmento social e melhorar a gestão dos resíduos sólidos. Este artigo tem como objetivo verificar em que medida o Programa Ecocidadão Paraná consegue auxiliar alguns municípios paranaenses a cumprir as exigências dispostas na Lei 12.305/10. Ainda, o presente artigo analisa alguns desafios enfrentados pelos municípios brasileiros na gestão de resíduos sólidos. Para alcançar estes objetivos foi realizada pesquisa bibliográfica por meio de análise de dispositivos legais e análise quali-quantitativa de documentos secundários, como dados e relatórios provenientes da fonte direta e dossiês de órgão públicos e privados. A partir da pesquisa, foi possível verificar que o Programa Ecocidadão é um meio interessante de melhorar a produção de reciclados, contudo é limitado quanto à inserção social dos catadores de materiais recicláveis e reutilizáveis.

Palavras-chave: Desenvolvimento sustentável. Responsabilidade socioambiental. Lei 12.305/10. Política Nacional de Resíduos Sólidos. Catadores de materiais recicláveis e reutilizáveis.

\footnotetext{
${ }^{1}$ Mestre em Direito Empresarial e Cidadania pelo Centro Universitário Curitiba - UNICURITIBA. Graduada em Direito pela Faculdade de Direito de Curitiba - UNICURITIBA. Pesquisadora nas áreas de Direito Empresarial e Ambiental. Instituição: Centro Universitário Curitiba - UNICURITIBA, Paraná. Brasil. E-mail: z.paloma@hotmail.com

2 Sociólogo. Pesquisador Docente do Programa de Pós-Graduação em Meio Ambiente e Desenvolvimento (PPGMADE-UFPR) e do Mestrado em Direito do UNICURITIBA. Instituição: Centro Universitário Curitiba UNICURITIBA, Paraná. Brasil. E-mail: zecaed@hotmail.com
} 


\section{ABSTRACT}

From Law 12,305/10, which instituted the National Solid Waste Policy, it became the municipal's duty to draw up solid waste management plans, to encourage the creation and strengthening of cooperatives and associations of recyclable and recyclable waste collectors, among other instruments that seek to ensure the proper management of solid waste. The Ecocity Paraná Program proposes to assist Cooperatives and Associations of collectors of recyclable and reusable materials, in order to promote the strengthening of this social segment and improve solid waste management. This article aims to verify to what extent the Ecocity Paraná Program can help some municipalities of Paraná to comply with the requirements established in Law 12.305/10. Moreover, the present article analyzes some challenges faced by Brazilian municipalities in solid waste management. To achieve these objectives, a bibliographic research was carried out through analysis of legal provisions and qualitative and quantitative analysis of secondary documents, such as data and reports from the direct source and public and private organ dossiers. From the research, it was possible to verify that the Ecocity Program is an interesting way of improving the production of recycled products, however it has limited effectiveness on social insertion of the collectors of recyclable and reusable materials.

Keywords: Sustainable development. Socio-environmental responsibility. Law 12.305/10. National Policy on Solid Waste. Collectors of recyclable and reusable materials.

INTRODUÇÃO

Desde a promulgação da Constituição da República de 1988, os municípios são considerados entes federativos autônomos, dotados de independência legislativa, administrativa e financeira, competências próprias. Ainda, contemplados com a possibilidade de suplementar a legislação federal e a estadual e, também, organizar e prestar, diretamente ou sob regime de permissão ou concessão, serviços públicos de interesses local e caráter essencial (Art. 30 incisos I, II e V, CR/88). 
Além disso, a Constituição Federal ainda determina a competência comum entre a União, o Distrito Federal, os Estados e os Municípios para proteger o meio ambiente e combater a poluição em qualquer de suas formas (art. 23, inciso VI, CR). Desse modo, a partir da interpretação sistemática dos dispositivos constitucionais, os municípios são titulares dos serviços de limpeza urbana e de gestão, gerenciamento e manejo dos resíduos sólidos, desde a coleta até a destinação final ambientalmente adequada.

Contudo, embora existissem normas que abordassem sobre a temática dos resíduos sólidos, especialmente as Resoluções do Conselho Nacional de Meio Ambiente - CONAMA, antes da Lei 12.305/10 não havia ${ }^{3}$ no Brasil nenhum instrumento legal que estabelecesse diretrizes e se dedicasse exclusivamente à temática dos resíduos sólidos, a fim de nortear os Estados e os Municípios na gestão adequada 4 .

Conforme a Pesquisa Nacional de Saneamento Básico (PNSB) realizada em 1989 pelo Instituto Brasileiro de Geografia e Estatística (IBGE), apenas 10,7\% dos municípios brasileiros destinavam adequadamente seus resíduos sólidos e 88,2\% dos resíduos sólidos urbanos tinham como seu destino final os vazadouros a céu aberto - os lixões.

Nos anos 2000, pesquisas realizadas pelo IBGE e pela Associação Brasileira de Empresas de Limpeza Pública e Resíduos Especiais (Abrelpe), notaram que a grande maioria dos municípios do país dispunham os resíduos sólidos urbanos em vazadouros a céu aberto ou em áreas alagadas, correspondendo a 72,25\% do universo pesquisado (ABRELPE, 2003). Em 2008, houve uma melhora relativa neste cenário com a diminuição da disposição dos resíduos sólidos em lixões e o aumento da participação dos aterros sanitários, de acordo com o Quadro 1.

Quadro 1: Destino final dos resíduos sólidos por unidades de destinos dos resíduos no Brasil.

\begin{tabular}{|c|c|c|c|}
\hline \multicolumn{4}{|c|}{ Destino final dos resíduos sólidos, por unidades de destinos dos resíduos (\%) } \\
\hline Ano & Vazadouro a céu aberto & Aterro controlado & Aterro sanitário \\
\hline 1989 & 88,2 & 9,6 & 1,1 \\
2000 & 72,3 & 22,3 & 17,3 \\
2008 & 50,8 & 22,5 & 27,7 \\
\hline
\end{tabular}

FONTE: IBGE, 2000 e 2008

É importante esclarecer a diferença entre aterros sanitários, aterros controlados e vazadouros a céu aberto - lixões: os aterros sanitários são construídos conforme normas da

\footnotetext{
${ }^{3}$ Cabe frisar que a Lei Federal № 11.445/07, já abordava alguns aspectos relevantes sobre o serviço público de limpeza urbana e de manejo de resíduos sólidos urbanos.

${ }^{4}$ Cabe salientar que a União não possui competência privativa para legislar sobre resíduos sólidos (MACHADO, 2014, p. 635).
} 
Associação Brasileira de Normas Técnicas (ABNT) e necessitam de um conjunto de sistemas como impermeabilização do solo, coberturas, manutenção e controle a fim de proteger o meio ambiente e a saúde pública; em contrapartida, nos vazadouros a céu aberto os resíduos sólidos são simplesmente jogados e amontoados em enormes depósitos ao ar livre, sem possuir nenhum tratamento adequado; nos aterros controlados, os resíduos sólidos são dispostos de maneira controlada e recebem uma cobertura de solo, contudo do ponto de vista ambiental, pouco se diferem dos lixões, já que não há o conjunto de sistemas necessários para proteger a saúde pública e o meio ambiente (FOGAÇA, 2014).

Feita a observação, não obstante o cenário tenha, ao longo dos anos que foram mostrados no Quadro 1, demonstrado melhora gradativa, principalmente nas Regiões Sul e Sudeste do país, a situação sobre a destinação reconhecidamente inadequada dos resíduos ainda era preocupante, e exigia soluções inexoráveis para o setor. Para tanto, tais soluções demandam mudanças sociais, legislativas, econômicas e culturais.

Como réplica dessas demandas, foi sancionada em 02 de agosto e regulamentada em 23 de dezembro de 2010 a Lei 12.305 que institui a Política Nacional de Resíduos Sólidos (PNRS), a qual dispõe de instrumentos, diretrizes e objetivos a fim de realizar à gestão integrada e correta dos resíduos sólidos.

A PNRS foi um marco no ordenamento jurídico pátrio, pois de maneira exclusiva e inédita a lei trata de todas as espécies de resíduos sólidos ${ }^{5}$ (exceto resíduos radioativos que são tratados por lei específica - Lei 10.308/01) e também regulamenta a gestão dos rejeitos ${ }^{6}$, a fim de promover a destinação adequada e estabelecer responsabilidades ao integrar Poder Público, empresas e cidadãos. A relevância do tema e sua regulamentação legal, portanto, é um passo relevante para que o país se desenvolva de modo sustentável e com consciência ambiental.

A despeito disso, a PNRS enfrenta grandes dificuldades de sair do papel. Segundo o Ministério do Meio Ambiente (BRASIL, 2018a) o quadro institucional, apesar de encontrar-se em estado de evolução, é negativo. A maioria das Prefeituras Municipais ainda não dispõe de recursos financeiros e técnicos para sanar os problemas relacionados à gestão dos resíduos sólidos urbanos (BRASIL, 2018a). Além disso, frequentemente não utilizam das possibilidades de estabelecer parcerias com outros setores sociais que deveriam estar envolvidos nessa gestão e na busca de alternativas para reais soluções. Os municípios raramente aproveitam as vantagens da cooperação com outros entes federados mediante consórcios públicos previstos pela Lei de Consórcios Públicos

\footnotetext{
${ }^{5}$ Domésticos, eletroeletrônicos, industriais, entre outros.

${ }^{6}$ Resíduos que não podem ser reutilizados ou reciclados (BRASIL, 2017a).
} 
(Lei № 11.107/2005), e pela Lei de Saneamento Básico (Lei № 11.445/2007) e seus respectivos decretos de regulamentação, Decreto no 6.017/2007 e Decreto № 7217/2010. Assim, a gestão de resíduos sólidos sem prévio planejamento técnico-econômico adequado continua frequente (BRASIL, 2018a).

Para melhorar a gestão de resíduos, a PNRS incentiva a parceria com cooperativas e/ou associação de catadores de materiais reutilizáveis e recicláveis. A lei presta atenção especial aos catadores de materiais recicláveis e reutilizáveis e estabelece que a participação da cooperativas/associações de catadores na coleta seletiva e na logística reversa é essencial, visto as contribuições muito significativas para o processo de reciclagem, já que trabalham desde o processo de coleta seletiva, passando também pela triagem, pela classificação, processamento, até a comercialização dos resíduos sólidos.

O fortalecimento das associações e/ou cooperativas de catadores é de grande importância para a eficácia da PNRS e de seus instrumentos, vez que proporciona, além dos benefícios ao meio ambiente (como o aumento de vida útil dos aterros sanitários dos municípios, por meio da gestão adequada dos resíduos, de modo a reduzir a quantidade de resíduos recicláveis e reutilizáveis dispostos nesses locais, e fazê-los retornar ao ciclo produtivo), também oferece a possibilidade de benefícios econômicos e sociais.

Dentro deste cenário, o Programa Ecocidadão Paraná foi criado em 2011 pelo Programa do Voluntariado Paranaense (Provopar) em convênio técnico-financeiro com a Companhia de Saneamento Básico do Paraná (Sanepar). Este programa possui cunho social e se propõe a dar auxílio às associações e/ou cooperações de catadores de materiais recicláveis e reutilizáveis, por meio de cursos técnicos de capacitação (PROVOPAR ESTADUAL, 2018).

\section{A TENTATIVA DE ERRADICAR OS LIXÕES E AS PRINCIPAIS DIFICULDADES DOS MUNICÍPIOS BRASILEIROS}

$\mathrm{O}$ art. 15, V, da Lei 12.305/10 procura melhorar a questão dos vazadouros a céu aberto, ao determinar que a União elaborará, sob a coordenação do Ministério do Meio Ambiente, o Plano Nacional de Resíduos Sólidos. Com vigência por prazo indeterminado e horizonte de 20 (vinte) anos, a ser atualizado a cada quatro anos, deve obrigatoriamente conter metas que tenham como objetivo eliminar e recuperar os vazadouros a céu aberto (lixões), à inclusão social e à emancipação econômica de catadores de materiais reutilizáveis e recicláveis. 
No Estado do Paraná, por exemplo, houve uma melhora em relação à destinação dos resíduos sólidos urbanos após a Política Nacional de Resíduos Sólidos. Segundo o Instituto Ambiental do Paraná (IAP), em 2013, dos 399 municípios paranaenses, 185 (46,4\%) municípios dispunham os resíduos sólidos em aterros sanitários, 121 (30,3\%) em aterros controlados e 93 (23,3\%) em lixões. O relatório divulgado em 2017 pelo IAP apontou que 301 cidades do Paraná (75\%) destinam seus resíduos a aterros sanitários licenciados, 74 (19\%) dispõem os resíduos em aterros controlados, mas ainda $24(6 \%)$ municípios destinam seus resíduos aos vazadouros a céu aberto (INSTITUTO AMBIENTAL DO PARANÁ, 2017).

Alessandra Mayumi Nakamura, engenheira química do IAP e coordenadora do levantamento dos dados do relatório, afirma que:

É possível perceber a redução no número de lixões e de aterros controlados, principalmente porque as prefeituras optaram por destinar os resíduos em aterros particulares ou através de consórcios.

(...)

Isso tem ocorrido muito com os municípios de pequeno porte, que têm dificuldade tanto financeira como de equipe técnica qualificada para fazer a implantação e gestão de um aterro, afirma (INSTITUTO AMBIENTAL DO PARANÁ, 2017).

Em especial tal questão da eliminação e recuperação dos lixões, é uma grande dificuldade enfrentada pela lei e que vêm encontrando entraves para sair do papel. Inicialmente a PNRS estipulou o prazo de 04 anos, sendo assim até agosto de $2014^{7}$, para a eliminação dos lixões e sua substituição pelos aterros sanitários. Apesar disso, foi levantando em torno de três mil lixões no país até o ano passado (BRASIL, 2017a). Segundo a Câmara dos Deputados, em 2017, ou seja, com 07 anos de vigência, a PNRS conseguiu eliminar os lixões em apenas $40 \%$ dos municípios brasileiros.

As dificuldades para erradicação dos lixões no Brasil são várias. Entre estas estão principalmente: a falta de planejamento e de regularização ambiental do serviço de coleta, a alta onerosidade para os municípios executarem o tratamento e a destinação ambientalmente adequada dos resíduos, e a escassez de funcionários especializados em manejo de resíduos (BRASIL, 2017c).

O coordenador da Frente Parlamentar em Defesa da Política Nacional de Resíduos Sólidos, o deputado Victor Mendes do PMDB do Maranhão, afirmou, em entrevista à Câmara dos Deputados, que a Lei 12.305/10 é boa, contudo devido as obrigações não estarem divididas igualmente entre o poder público e o setor privado, enfrenta dificuldades para a sua implementação. Na ocasião da entrevista ele afirmou que:

Tratar resíduo é caro. Não adianta só gerar mais uma obrigação, com possibilidade de punição dos gestores municipais sem fazer parceria, sem estender a mão, sem orientar. Apenas terceirizando, depois cobrando, depois

\footnotetext{
${ }^{7}$ O Senado prorrogou esse prazo para 2021 (BRASIL, 2016a).
} 
punindo, como está acontecendo hoje. A gente quer que essa lei, que é uma lei bem feita, que é modelo para todo o mundo, mas que ela não seja modelo apenas na teoria, mas que ela também seja um bom modelo na prática. Que o Brasil entre no protagonismo também do tratamento de resíduos, que está muito longe disso acontecer (BRASIL, 2017c).

Nesse contexto, vale destacar o Lixão Estrutural ${ }^{8}$ : desativado em janeiro de 2018, era o maior lixão da América Latina e estava localizado a apenas 15 km do centro do governo federal em Brasília. A diretora presidente do Serviço de Limpeza Urbana do Distrito Federal - SLU, Heliana Kátia Tavares Campos, em entrevista à reportagem publicada pela Câmara dos Deputados, explicou que o encerramento do Lixão Estrutural não era um problema apenas do SLU, visto que não se tratava de questão de técnica somente, mas englobava muitas áreas:

Em dois meses que eu estava aqui eu descobri que lá tinha: desova de carro roubado queimado, tráfico de entorpecentes, venda de alimentos vencidos e vincendos, poluição do subsolo com horta ali do lado. Fizemos uma reunião com o governador e falamos: quem tem que lidar com isso aqui são 17 órgãos. Então, o SLU não sabe lidar com esse tanto de questões. (BRASIL, 2017d)

Desse modo, a gestão dos resíduos sólidos no Brasil vai muito além de problemas ambientais e de saúde pública. Trata-se de uma problemática muito mais profunda, a qual envolve cidadania, questões sociais, segurança e trabalho. O problema da gestão dos resíduos sólidos no país, portanto, não se trata apenas de problemas técnicos, tecnológicos e normativos, mas principalmente de problemas institucionais e estruturais da própria sociedade brasileira.

Segundo Ariovaldo Caodaglio, presidente do Sindicato das Empresas de Limpeza Urbana do Estado de São Paulo (Selur), no caso do Lixão Estrutural, um sério problema enfrentado pelas autoridades durante o processo de desativação, foi o destino dos 2 mil catadores que trabalhavam no local (MENEZES, 2016).

Apesar de a Lei 12.305/10 tratar de algumas dessas questões ao incentivar o fortalecimento das cooperativas e/ou associações de catadores, visando melhorar a qualidade de vida, a renda e propiciar a autonomia desse segmento social, de acordo com o representante do Movimento Nacional dos Catadores, Ronei Alves da Silva, na prática a lei não é eficaz ao melhorar a vida dos catadores. Na realidade, Ronei afirma que os catadores são responsáveis pela coleta seletiva e pela reciclagem, porém ainda não ganharam espaço para trabalhar e continuam vivendo em situações precárias (BRASIL, 2017d).

\footnotetext{
${ }^{8}$ O Lixão Estrutural era o segundo maior do mundo: com uma área de 201 hectares, o equivalente a cerca de 280 campos de futebol. Estimativas do Serviço de Limpeza Urbana (SLU) afirmam que cerca de 40 milhões de toneladas de lixo foram aterradas no Lixão Estrutural desde a década de 1960, quando a área começou a ser utilizada para esse fim. Em 2016, foram depositadas 830.055 toneladas de resíduos domiciliares (BRASIL, 2018b).
} 
Assim, além dos benefícios ambientais, o fortalecimento das cooperativas e/ou associações é de grande importância do ponto de vista sustentável, vez que o trabalho dos catadores de materiais recicláveis junto às associações proporciona melhora nas condições de vida e de trabalho, na dignidade da pessoa humana, na economia solidária com inclusão dessas famílias quanto à geração de renda e no desenvolvimento sustentável.

\section{O PROGRAMA ECOCIDADÃO PARANÁ}

Com o propósito de auxiliar e incentivar as cooperativas e associações de catadores de materiais recicláveis e reutilizáveis, surgiu o Programa Ecocidadão Paraná, que tem como base a Lei 12.305/10 e trabalha a fim de capacitar os catadores e estimulá-los a participar e intensificar ações de educação ambiental, tanto em relação à técnica de separação e manejo adequado dos resíduos sólidos, quanto à educação no que diz respeito à sensibilização de porta a porta sobre valores e princípios sustentáveis.

O Programa tem cunho social e é realizado pelo Provopar Estadual ${ }^{9}$ e pela Companhia de Saneamento do Paraná - Sanepar, por meio de convênio técnico-financeiro. Teve início nos municípios do litoral do Paraná em dezembro de 2011 e atualmente atua em 67 municípios paranaenses. Ao total, de dezembro de 2011 até janeiro de 2018, o Programa Ecocidadão Paraná atendeu 197 municípios paranaenses e mais de 2,4 mil famílias de catadores em estado de vulnerabilidade social. Além disso, nesses sete anos o programa proporcionou auxílio e orientação a 213 associações/cooperativas de catadores de materiais recicláveis ou reutilizáveis, o que possibilitou a destinação adequada de 78 mil toneladas de materiais recicláveis que foram retirados do meio ambiente por catadores capacitados pelo Programa (PROVOPAR, 2018).

A partir da capacitação dos catadores de materiais recicláveis e reutilizáveis e dos demais auxílios fornecidos, o Programa Ecocidadão, busca alcançar os seguintes resultados:

I. Orientação, organização e apoio às associações e cooperativas de catadores de materiais recicláveis do Estado quanto a organização administrativa, física e comercial, promovendo a inclusão e o fortalecimento de catadores na cadeia da reciclagem.

II. Apoio na comercialização do material reciclável de associações de catadores, visando melhorar o escoamento do reciclável.

9 O Provopar Estadual é uma associação civil, com personalidade jurídica de direito privado, sem fins econômicos e lucrativos que trabalha com objetivo de dar assistência social, educacional, beneficente, cultural, ambiental, saúde e geração de renda aos municípios paranaenses (PROVOPAR, 2018). 
III. Adequação e otimização das instalações de associações e cooperativas, através da oferta de equipamentos (prensa, balança, mesa de separação, EPI, uniforme, big bags, etc.).

IV. Promoção da inclusão social do catador no que se refere à geração de trabalho e renda, permitindo sustentabilidade econômica e o fomento ao desenvolvimento local.

V. Destinação de todo resíduo reciclável do município para associações de catadores, conforme estabelece a Política Nacional de Resíduos Sólidos (Lei nำ12.305/10).

VI. Capacitação técnica e gerencial a associados e cooperados, realizada pelos técnicos do convênio entre Sanepar e Provopar Estadual. O trabalho inicia com um Diagnóstico, seguido da fase de Sensibilização e Capacitação, Qualificação e Gestão, Produção e Comercialização, tendo como objetivo final a autonomia dos catadores e a autogestão do empreendimento.

VII. Aumento da vida útil de aterros sanitários dos municípios, através da atuação dos catadores no que se refere à coleta seletiva, logística reversa e a triagem dos materiais.

VIII. Implantação de um modelo tecnológico misto que privilegia a minimização da geração e o manejo diferenciado de resíduos sólidos, com a triagem e a recuperação dos resíduos que constituem bem econômico e valor social, e a disposição final exclusivamente dos rejeitos, de forma ambientalmente adequada (PROVOPAR, 2018).

Para possibilitar o trabalho do Programa, são disponibilizados ${ }^{10} \mathrm{em}$ sistema de cessão de uso para o trabalho de separação dos materiais recicláveis e/ou reutilizáveis e mediante diagnóstico da capacidade operacional das associações/cooperativas de catadores pelos técnicos do projeto social, às associações/cooperativas equipamentos básicos para manejo dos resíduos sólidos como: elevador de fardo, carrinhos de movimentação de fardo, equipamentos de proteção individual (EPI), mesas de triagem, balanças e prensas. ${ }^{11}$

Os municípios interessados em obter os auxílios do Programa Ecocidadão Paraná, devem obrigatoriamente, possuir associação ou cooperativa de catadores de materiais recicláveis ou reutilizáveis legalmente constituída e formalizada. ${ }^{12}$

Contudo, não há ônus a ser suportado pela prefeitura dos municípios, vez que os equipamentos para a execução do trabalho social são fornecidos pela Sanepar em regime de cessão de uso para as associações/cooperativas de catadores, e a capacitação é realizada pelos técnicos do Programa.

\footnotetext{
${ }^{10}$ Há municípios em que não é necessário haver cessão para uso de tais equipamentos, tendo em vista o apoio de suas prefeituras que atuam ativamente fornecendo espaço, equipamentos e maquinários, e ainda em alguns casos, funcionários técnicos para trabalhar, durante 8 horas diárias, dentro da associação/cooperativa. ${ }^{11} \mathrm{~A}$ cessão de uso de tais equipamentos devem respeitar o plano orçamentário aprovado com a supervisão da Sanepar.

${ }^{12}$ Para os municípios que não possuem associação/cooperativa legalmente constituída e formalizada, e têm interesse em participar, o Programa EcoCidadão Paraná prevê orientação e auxílio para constituir e formalizar grupos de catadores locais.
} 
Por fim, antes de expor a síntese dos resultados do Programa, é importante destacar que para realizar o estudo do Programa Ecocidadão Paraná, foi feita a coleta e a análise quali-quantitativa de documentos secundários, como dados e relatórios técnicos provenientes da fonte direta, o Programa Voluntariado Paranaense - Provopar Estadual.

\section{SÍNTESE DOS RESULTADOS DO PROGRAMA ECOCIDADÃO PARANÁ}

A partir da pesquisa realizada, foi possível constatar que o trabalho executado pelo Programa Ecocidadão Paraná consegue cumprir muitos dos seus objetivos, como, por exemplo, otimizar as instalações de associações e cooperativas por meio da oferta de equipamentos, gerar aumento de renda familiar dos catadores e aumentar a produção de reciclagem, bem como a diminuir os materiais recicláveis e reutilizáveis dispostas nos aterros sanitários.

Ainda, o Programa atingiu seu objetivo no tocante ao fortalecimento das associações/cooperativas de catadores de materiais recicláveis e reutilizáveis, vez que aumentou em 1000\% o número de cooperativas inscritas que tiveram o auxílio do programa desde o seu início até o ano de 2016. No quadro 2 demonstra-se o comparativo de associações/cooperativas integrantes do Programa Ecocidadão Paraná a cada ano de 2011 a 2016:

Quadro 2: Número de associações que participaram do Programa Ecocidadão Paraná durante o período de 2011 a 2016.

\begin{tabular}{|c|c|c|c|}
\hline ANO & $\begin{array}{c}\text { ASSOCIAÇÕES QUE } \\
\text { INGRESSARAM }\end{array}$ & $\begin{array}{c}\text { ASSOCIAÇÕES QUE } \\
\text { SAIRAM }\end{array}$ & TOTAL \\
\hline 2011 & 7 & 0 & 7 \\
2012 & 4 & 0 & 11 \\
2013 & 23 & 0 & 34 \\
2014 & 16 & 0 & 50 \\
2015 & 18 & 6 & 62 \\
2016 & 15 & 0 & 77 \\
\hline
\end{tabular}

FONTE: PROVOPAR, 2016

Seis associações se desligaram do Programa Ecocidadão Paraná no ano de 2015, pois não possuíam espaço (barracão) e/ou não tinham verba suficiente para arcar despesas como eletricidade. Além disso, as respectivas prefeituras não forneceram barracões e/ou auxílio financeiro, de modo que se tornou inviável a continuidade dos trabalhos do Programa. ${ }^{13}$

13 Ressalta-se que as prefeituras não possuem ônus algum, o que ocorre, no entanto, é que em muitos municípios elas prestam auxílio às cooperativas/ associações no que se refere ao fornecimento do espaço para trabalho, e verbas para gastos como luz, água e manutenção dos barracões. 
Ademais, conforme dados do Provopar, em 2017 o Programa Ecocidadão Paraná totalizou o número de 104 municípios paranaenses atendidos, sendo 65 deles no primeiro semestre de 2017 e o restante no segundo. Ainda, um total de 844 catadores foram beneficiados pelo Programa no ano de 2017 e 2.444 catadores desde o início (em 2011) até o final do ano de 2017.

Quanto à geração de renda, conforme a análise dos dados disponibilizados pelo Provopar, o Programa Ecocidadão Paraná conseguiu aumentar o rendimento financeiro mensal dos catadores. A título de demonstração e comparação dos resultados, foi feito o levantamento dos números referentes aos municípios paranaenses atendidos no primeiro semestre do ano de $2016^{14}$ :

1) Castro, 71.501 habitantes (2017) e índice de desenvolvimento humano (IDH) de 0,703 (2010) (INSTITUTO PARANAENSE DE DENSENVOLVIMENTO ECONÔMICO E SOCIAL, 2018a).

A renda média mensal dos catadores anteriormente ao Programa Ecocidadão Paraná, contabilizava $\mathrm{R} \$ 400,00$. No fim do primeiro semestre de 2016, em junho, a renda média mensal dos catadores era de $\mathrm{R} \$ 500,00$.

Conforme relatório do Programa, o número de associados totalizou 15 (quinze) catadores. O município de Castro possui coleta seletiva, aterro sanitário e realiza atividades de Educação Ambiental com a população. A coleta de recicláveis é realizada por empresa terceirizada em dias alternados a coleta dos resíduos orgânicos. O barracão em que os catadores trabalham foi cedido pela prefeitura municipal e possui edícula com vestiário e refeitório. Os equipamentos (carrinho de fardo, prensa e balança) foram cedidos por parceiros do projeto, as empresas Tetra Pak e Castrolanda. Ao Ecocidadão Paraná foi solicitado apenas uma mesa de separação. Cerca de três toneladas de resíduos sólidos foram recicladas no primeiro semestre de trabalho do Programa.

Os pontos positivos apontados pelos técnicos do Ecocidadão Paraná foram sobre a associação ser participativa e o barracão limpo e organizado. Em contrapartida, os pontos negativos elencados foram de que a prefeitura é ausente em relação à gestão dos resíduos; a associação não possuía CNPJ o que dificulta os andamentos burocráticos de empréstimo de equipamentos, por exemplo; e a falta de segurança, foram constatados roubos frequentemente no barracão (PROVOPAR ESTADUAL, 2016).

2) Bandeirantes, 32.486 habitantes (2017) e IDH 0,727 (INSTITUTO PARANAENSE DE DENSENVOLVIMENTO ECONÔMICO E SOCIAL, 2018b).

\footnotetext{
${ }^{14}$ Foi escolhido o primeiro semestre do ano de 2016 para a demonstração dos resultados, pois conforme a pesquisa realizada, este foi o período em que foi possível obter dados mais completos e precisos a partir dos documentos fornecidos pelo Provopar Estadual.
} 
Anteriormente ao Programa Ecocidadão Paraná, a renda média mensal dos catadores contabilizava $\mathrm{R} \$ 370,00$. Ao final do primeiro semestre de 2016, em junho, a renda média mensal dos catadores subiu para $\mathrm{R} \$ 600,00$.

Conforme relatório do Programa, o número de associados foi de 15 (quinze) catadores. Em 2016, o município tinha recém desativado o lixão municipal e estava destinando os rejeitos para um aterro sanitário de empresa terceirizada chamada INOVA, que realiza a coleta seletiva de recicláveis em dias alternados à coleta de resíduos orgânicos. O município iniciou, em 2015, programa de Educação Ambiental com a população. O barracão para trabalho foi cedido pela prefeitura. 0 Programa forneceu à associação: um carrinho de fardo, uma mesa de triagem, uma prensa e uma balança. Foram recicladas cerca de quatro toneladas de resíduos durante o primeiro semestre de trabalho do Programa Ecocidadão Paraná.

De acordo com as observações feitas pelos técnicos, o grupo de catadores foi unido e participativo e a prefeitura é presente e atuante nas associações junto aos catadores, e ainda, fornecia cesta básica. O único ponto negativo citado foi que a renda média mensal ainda não conseguiu equiparar o salário mínimo da época (PROVOPAR ESTADUAL, 2016).

3) Guaratuba, 35.986 habitantes (2017) e IDH 0,717 (INSTITUTO PARANAENSE DE DENSENVOLVIMENTO ECONÔMICO E SOCIAL, 2018c).

A renda média mensal dos catadores perfazia $\mathrm{R} \$ 450,00$ antes do Programa Ecocidadão Paraná. Ao final do primeiro semestre de 2016, a renda média mensal foi de $\mathrm{R} \$ 600,00$. O número de associados foi de 21 catadores e cerca de dez toneladas recicladas no primeiro semestre junto ao Programa.

Conforme o relatório, o barracão foi cedido pela prefeitura e no mesmo local, anteriormente, havia outra Associação que recebeu do Programa Ecocidadão Paraná, em 2012, uma prensa e uma balança. Quando esta associação se extinguiu, foi constituída nova diretoria e associados. No entanto, os equipamentos cedidos continuaram sendo utilizados pelo novo grupo. A associação solicitou um elevador de fardo, que foi cedido pelo Programa.

Foram elencados vários pontos positivos no trabalho em Guaratuba: a associação determinada, participativa e criativa; o barracão limpo e organizado; a prefeitura atuante e presente, e ainda disponibilizava uma técnica para trabalhar junto aos catadores durante 8 horas diárias; a prefeitura ajudava também com busca constante de parcerias; ocorreu o acompanhamento do Centro de Referência de Assistência Social de Guaratuba (CRAS), da secretaria da saúde que ajudou com vacinas e do clube Rotary que prestou serviços de alfabetização aos associados. 
Entretanto, algumas dificuldades enfrentadas no trabalho de gestão dos resíduos foram a grande quantidade de deficientes e idosos, e a necessidade de complementar a renda dos catadores com cesta básica. (PROVOPAR ESTADUAL, 2016)

4) Piraí do Sul, 25.277 habitantes (2017) e IDH 0,708 (INSTITUTO PARANAENSE DE DENSENVOLVIMENTO ECONÔMICO E SOCIAL, 2018d).

O número de associados era de quatro catadores. A renda média dos catadores antes do Programa era $\mathrm{R} \$$ 430,00 e a renda após o primeiro semestre de 2016 não constava no relatório, pois a informação não foi repassada aos técnicos do Provopar. A associação possuía barracão e alguns equipamentos como prensa, balança e mesa de triagem cedidos pela prefeitura. O volume total de resíduos reciclados foi cerca de duas toneladas.

Segundo os técnicos, o barracão e os equipamentos estavam em ótimas condições, a associação participativa e a prefeitura atuante e presente. Em contrapartida, o número de associados era baixo, pois poucas pessoas na cidade estavam interessadas em trabalhar com reciclagem e houve problemas devido ao extravio de documentação; além da constatação de pouca separação de resíduos recicláveis pela população. (PROVOPAR ESTADUAL, 2016)

Desse modo, conforme o exposto, resumido no quadro 3, a renda dos catadores teve em média alta de $40 \%$ após o trabalho do Programa Ecocidadão Paraná. Sendo assim, no primeiro semestre de 2016, o projeto social conseguiu atingir parcialmente sua meta no que diz respeito à inclusão social dos catadores através do aumento de renda dos associados, vez que nenhuma associação participante do Programa neste período conseguiu atingir o salário mínimo da época que perfazia $\mathrm{R} \$ 880,00$.

Quadro 3: Comparativo da renda média dos catadores antes e depois do Programa Ecocidadão Paraná no primeiro semestre de 2016.

\begin{tabular}{|l|c|c|}
\hline Município & Renda média anterior (R\$) & Renda média posterior (R\$) \\
\hline Castro & 400 & 600 \\
Bandeirantes & 370 & 600 \\
Guaratuba & 450 & 600 \\
\hline
\end{tabular}




\begin{tabular}{|l|l|l|} 
Piraí do Sul & 430 & não informado \\
\hline
\end{tabular}

FONTE: PROVOPAR, 2016

A despeito disso, o Provopar Estadual afirmou já ter conseguido atingir integralmente esse objetivo algumas vezes, como, por exemplo, no primeiro semestre de 2014, conforme o quadro 4.

Quadro 4: Comparativo da renda média dos catadores antes e depois do Programa Ecocidadão Paraná no primeiro semestre de 2014.

\begin{tabular}{|l|c|c|}
\hline Município & Renda média anterior (R\$) & Renda média posterior (R\$) \\
\hline Pitangueiras & 600 & 800 \\
Matinhos & 600 & 891 \\
Telemaco Borba & 600 & 960 \\
Rio Branco & 700 & 966 \\
\hline
\end{tabular}

FONTE: PROVOPAR, 2014

Sendo assim, é possível notar que a renda dos catadores aumentou em média, aproximadamente, $45 \%$. Além disso, todos os municípios citados no quadro 4 conseguiram superar o salário mínimo da época que era $\mathrm{R} \$ 724,00$.

Portanto, quanto ao aumento de renda e o fortalecimento desse segmento social através das associações e cooperativas, o Programa Ecocidadão Paraná demonstra de modo geral resultados interessantes, vez que conseguiu possibilitar que a renda referente aos materiais reciclados seja destinada aos catadores diretamente. No entanto, apresenta limitações visto que em alguns períodos e municípios específicos não conseguiu atingir o salário mínimo da época, o que deixa a desejar quanto à inclusão social.

Vale ressaltar que conforme os relatórios dos técnicos do Provopar, o trabalho do Programa parece se desenvolver melhor e apresenta melhores resultados quando a prefeitura tem presença ativa no auxílio aos catadores e a gestão dos resíduos sólidos.

Por meio do Programa Ecocidadão Paraná, foram recicladas 78 mil toneladas desde o seu início. É possível observar no quadro 5, que o índice de reciclagem aumentou a cada ano. Todavia, o 
número total de reciclados nos anos 2012, 2016 e 2017 não foi fornecido pela fonte (PROVOPAR, 2018).

Quadro 5: Produtividade do Programa Ecocidadão Paraná referente à reciclagem de materiais e separação de rejeitos nos anos de 2013, 2014 e 2015 (até outubro).

\begin{tabular}{|l|l|l|}
\hline \multicolumn{3}{|c|}{ Comparativo 2013 a 2015} \\
Produtividade de Reciclado e Rejeito (KG) \\
\hline Ano & Total Reciclado & Total Rejeito \\
\hline 2013 & 6.636 .988 & 1.974 .544 \\
\hline 2014 & 11.132 .998 & 3.284 .781 \\
\hline $\begin{array}{l}2015 \\
\text { outubro até }\end{array}$ & 11.160 .009 & 2.560 .168 \\
\hline
\end{tabular}

FONTE: PROVOPAR, 2015

Portanto, o Programa Ecocidadão Paraná apresentou bons resultados e cumpre seu objetivo no que se refere à destinação de materiais reciclados, a fim de diminuir o número de materiais dispostos em aterros, rios e mananciais. Da mesma forma, cumpre parcialmente as exigências da Lei 12.305/10 quanto à destinação adequada e a reciclagem dos resíduos sólidos.

\section{CONCLUSÃO}

Não obstante a gestão de resíduos sólidos no Brasil ter apresentado uma melhora gradativa desde a Política Nacional de Resíduos Sólidos, o quadro institucional ainda deixa a desejar, vez que o país ainda possui cerca de três mil lixões ativos, e ainda possui uma porcentagem ${ }^{15}$ significativa de resíduos sólidos urbanos que não possuem destinação ambientalmente correta.

A Política Nacional de Resíduos Sólidos ainda enfrente diversas dificuldades na sua aplicação prática: a maioria das prefeituras municipais não dispõe de recursos técnicos e financeiros para solucionar os problemas da gestão de resíduos sólidos. Ainda, a falta de planejamento, de regulação e controle social no setor também configuram problemas frequentes.

15 Em 2016, 9\% dos resíduos sólidos urbanos não foram coletados no Brasil, o que consequentemente acarretou na destinação incorreta desses resíduos. (ABRELPE, 2016). 
Desse modo, a questão da gestão dos resíduos sólidos ultrapassa os problemas puramente técnicos e/ou tecnológicos, e se mostra também um problema legislativo e social. O planejamento e a execução correta da gestão e do gerenciamento de resíduos sólidos são responsabilidades grandes e onerosas, que requerem altos recursos financeiros e técnicos.

A realidade brasileira demonstra que a maioria dos municípios não possui preparo, tampouco condições suficientes para realizar gestão dos resíduos sólidos de forma socioambientalmente adequada. Além disso, para que isso ocorra, é essencial a inserção social dos catadores de materiais recicláveis e reutilizáveis, visto tratar-se de um papel social fundamental na gestão integrada e que ganhou grande destaque na PNRS.

O Programa Ecocidadão Paraná criado em dezembro de 2011 nos municípios litorâneos do Paraná, pelo Provopar Estadual com convênio técnico-financeiro com a Sanepar, tem o intuito de colocar em prática alguns instrumentos da PNRS, principalmente o fortalecimento das cooperativas e associações de catadores de materiais recicláveis e reutilizáveis.

A partir da análise e da síntese dos resultados do Programa Ecocidadão Paraná, é possível concluir que o Programa consegue prestar auxílio aos municípios necessitados de modo significativo, visto o resultado obtido dos trabalhos realizados nos municípios menores do estado do Paraná, os quais não possuem grandes planejamentos e provisões orçamentárias para a gestão e gerenciamento adequado de resíduos sólidos e que, geralmente, dependem de serviços terceirizados de empresas particulares.

Além disso, o Programa Ecocidadão Paraná utiliza alguns dos principais instrumentos de gestão de resíduos sólidos determinados pela Lei 12.305/10, quais sejam: promover o fortalecimento da classe dos catadores de materiais recicláveis, a coleta seletiva, a responsabilidade compartilhada e a reciclagem.

Todavia, o Programa Ecocidadão Paraná mostrou possuir limitações quanto ao seu trabalho, visto que depende de muitas formalidades e ações que vão além da competência do Provopar Estadual e dependem de várias ações provenientes das prefeituras municipais e políticas públicas, como por exemplo, a estrutura necessária para os trabalhos (barracões - o Provopar disponibiliza aos catadores apenas os equipamentos), a formalização das associações e o sistema de coleta nos municípios.

\section{REFERÊNCIAS}

ABRELPE, 2003. Panorama dos Resíduos Sólidos no Brasil 2003. Disponível em http://www.abrelpe.org.br/Panorama/panorama2003.pdf. Acesso em: 08 mar.2018. 
2016. Panorama dos Resíduos Sólidos no Brasil 2016. Disponível em http://www.abrelpe.org.br/Panorama/panorama2016.pdf. Acesso em: 08 mar.2018.

BRASIL, 2016a. Disponível em: https://www12.senado.leg.br/noticias/materias/2016/07/29/lixoesa-ceu-aberto-voltam-a-ser-discutidos-no-senado. Acesso em 04 fe.2019.

BRASIL, 2017a. Política de Resíduos Sólidos enfrenta desafio de sair do papel. Disponível em: http://www2.camara.leg.br/camaranoticias/noticias/MEIO-AMBIENTE/447525-POLITICA-DERESIDUOS-SOLIDOS-ENFRENTA-DESAFIO-DE-SAIR-DO-PAPEL.html. Acesso em: 10 mar.2018.

BRASIL, 2017b. Lixões sem fim. Disponível em: http://www2.camara.leg.br/camaranoticias/tv/materias/PARTICIPACAO-POPULAR/522105-LIXOESSEM-FIM.html. Acesso em: 18 mar.18.

BRASIL, 2017c. Política Nacional de Resíduos Sólidos: dificuldades para implantação - Bloco 1. Disponível em: http://www2.camara.leg.br/camaranoticias/radio/materias/REPORTAGEMESPECIAL/523012-POLITICA-NACIONAL-DE-RESIDUOS-SOLIDOS-DIFICULDADES-PARAIMPLANTACAO-BLOCO-1.html. Acesso em: 17 mar.2018.

BRASIL, 2017d. Política Nacional de Resíduos Sólidos: situação atual dos lixões - Bloco 2. Disponível em: http://www2.camara.leg.br/camaranoticias/radio/materias/REPORTAGEM-ESPECIAL/523014POLITICA-NACIONAL-DE-RESIDUOS-SOLIDOS-SITUACAO-ATUAL-DOS-LIXOES-BLOCO-2.html. Acesso em: 18 mar.2018.

BRASIL, 2018a. Contexto e principais aspectos da Política Nacional de Resíduos Sólidos. Disponível em: http://www.mma.gov.br/cidades-sustentaveis/residuos-solidos/politica-nacional-de-residuossolidos/contextos-e-principais-aspectos. Acesso em: 05 mar.2018.

BRASIL, 2018b. Vida e morte do Lixão. Disponível em: https://www.agenciabrasilia.df.gov.br/especial/vida-e-morte-do-lixao/. Acesso em: 12 jun.2018.

INSTITUTO AMBIENTAL DO PARANÁ, 2017. 75\% dos municípios destinam resíduos para aterros licenciados. Disponível em: http://www.iap.pr.gov.br/2017/07/1243/75-dos-municipios-destinamresiduos-para-aterros-licenciados.html. Acesso em: 19 mai.2018. 
INSTITUTO PARANAENSE DE DESENVOLVIMENTO HUMANO E SOCIAL, 2018,a. Caderno estatístico município de Castro. Disponível em: http://www.ipardes.gov.br/cadernos/MontaCadPdf1.php?Municipio=84160. Acesso em: 02 jun.2018.

INSTITUTO PARANAENSE DE DESENVOLVIMENTO HUMANO E SOCIAL, 2018,b. Caderno estatístico município de Bandeirantes. Disponível em: http://www.ipardes.gov.br/cadernos/MontaCadPdf1.php?Municipio=86360. Acesso em: 02 jun.2018.

INSTITUTO PARANAENSE DE DESENVOLVIMENTO HUMANO E SOCIAL, 2018,c. Caderno estatístico município de Guaratuba. Disponível em: http://www.ipardes.gov.br/cadernos/MontaCadPdf1.php?Municipio=83280. Acesso em: 02 jun.2018.

INSTITUTO PARANAENSE DE DESENVOLVIMENTO HUMANO E SOCIAL, 2018,d. Caderno estatístico município de Piraí do Sul. Disponível em: http://www.ipardes.gov.br/cadernos/MontaCadPdf1.php?Municipio=84240. Acesso em: 02 jun.2018.

IBGE. Pesquisa Nacional de Saneamento Básico 2000. Disponível em: https://ww2.ibge.gov.br/home/presidencia/noticias/27032002pnsb.shtm. Acesso em: 08 mar.2018.

—. Pesquisa Nacional de Saneamento Básico 2008. Disponível em: https://biblioteca.ibge.gov.br/visualizacao/livros/liv45351.pdf. Acesso em: 08 mar. 2018.

FOGAÇA, Jennifer. Diferença entre lixão, aterro controlado e aterro sanitário. MUNDO EDUCAÇÃO, 2014 Disponível em: https://mundoeducacao.bol.uol.com.br/quimica/diferenca-entre-lixao-aterrocontrolado-aterro-sanitario.htm. Acesso em: 09 mar.2018.

MACHADO, Paulo Affonso Leme. Direito Ambiental Brasileiro. 22. ed. São Paulo: Malheiros, 2014. 
MENEZES, Delmo. Estudo aponta que o DF não cumpre metas da Política Nacional de Resíduos Sólidos. Agenda Capital, 03 jul. 2016. Disponível em: http://agendacapital.com.br/estudo-apontaque-o-df-nao-cumpre-metas-da-politica-nacional-de-residuos-solidos/. Acesso em: 12 jun.2016.

PROVOPAR ESTADUAL, 2018. Em 7 anos, Ecocidadão Paraná atendeu 197 municípios e mais de 1,6 mil famílias. Disponível em: http://www.provoparestadual.org.br/2018/01/2819/Em-7-anosEcocidadao-Parana-atendeu-197-municipios-e-mais-de-16-mil-familias.html. Acesso em: 09 mai.2018.

ZAMBON, Paloma. Limites e potencialidades do Programa Ecocidadão Paraná: estudo sobre os catadores de materiais recicláveis. Dissertação para o Programa de Mestrado em Direito Empresarial e Cidadania do Centro Universitário Curitiba, 2018.

Trabalho enviado em 16 de outubro de 2018 Aceito em 07 de fevereiro de 2019 